\title{
Innovation Ecosystem of Higher Educational Institution as a Driver of Commercialization of Intellectual Activity Results
}

\author{
Ekaterina A. Ugnich \\ Alexander I. Chernokozov \\ Elena V. Velichko
}

Don state technical university, Rostov-on-Don, Russia; E-mail: ugnich77@mail.ru

Doi:10.5901/mjss.2015.v6n6s1p239

\begin{abstract}
The solution of the problems of commercialization of university researches and development depends on effective functioning of innovative ecosystem of the university contributing to the transformation of scientific researches and development into a market product. This research work is devoted to the analysis of the problems of functioning of innovative ecosystem of the university. The objective of this research is a justification of innovation ecosystem significance and identification of its prospects in the development of commercialization of intellectual activity results in a higher educational institution. According to the authors, the prospects of development of innovative ecosystem of the university are considered in strategic development and interaction of its three basic components (constituents) which are carrying out stimulation of scientific researches, provision of their commercialization and formation of partnership organizational culture in total with necessary competences of innovative business.
\end{abstract}

Keywords: Innovation ecosystem, intellectual activity results.

\section{Introduction}

The milestone of the XX-XXI centuries was marked by radical transformations of higher educational system in the whole world. Today higher educational institutions are changing adjusting to new requirements of global information society. On the one hand, they have to carry out their classical function - to be the guarantor of universal values and cultural development, on the other hand, they have to make significant contribution to knowledge-based economy by means of commercialization of the results of science-research activity and development of entrepreneurial culture. In this regard, an important task of domestic higher educational institutions is considered to be the implementation of innovation activity through organization and development of the transfer of technologies and competences in real sector of economy. Realization of the assigned task depends in many respects on efficiency of the process of commercialization of intellectual activity results (IAR) which is reached in many respects thanks to the development of innovation ecosystem of a higher educational institution.

Ecosystem approach to the research of innovation process has found its reflection in the works of K. Fakuda and S. Vatanabe (2008), D. Jackson (2011), B. Mercan and D. Goktas (2011), N. Smorodinskaya (2014), etc. Despite considerable attention to this problem, many questions still remain unresolved, it concerns primarily the problem of process ensuring of RIA commercialization in higher educational institutions. Foreign experience has shown the importance of overcoming barriers on the way of innovations commercialization by means of the mechanisms of support and stimulation which are contained in innovation ecosystem of a higher educational institution.

The objective of this research is a justification of innovation ecosystem significance and identification of its prospects in the development of commercialization of intellectual activity results in a higher educational institution. The hypothesis of the research consists in the fact that efficiency of commercialization of intellectual activity results in a higher educational institution depends on the development of its innovation ecosystem in the basis of which should lie the principles of reasonability, interrelations between its agents, interrelations with the environment and provision of partnership organizational culture. 


\section{Method}

In the basis of the research lies the application of the methods of systemic analysis which let identify the essential characteristic features of the innovation infrastructure tools affecting commercialization of research activity results in a changing economic environment. The given research is also based on the consolidation of the principles of evolutionary economics (Nelson and Winter, 1982) and institutional theory (Freeman, 1987 Lundvall, 1992) according to which the institutions with the most favorable properties contributing to the effective development of society and economy are preserved and acquire further development. The empirical base of this study became the data of the Federal Service for Intellectual Property, the systems of accounting and monitoring of small innovation enterprises of scientific-educational sphere of the Ministry of Education and Science of the Russian Federation as well as the experience of some Russian Universities (NRU The Higher School of Economics, Saint Petersburg National Research University of Information Technologies, Mechanics and Optics (ITMO University), Don State Technical University and others) in the sphere of creation of innovation infrastructure for commercialization of innovations.

\section{Results}

Under commercialization of IAR in the University one can understand the process of transformation of Research and Development (R\&D) results, preserving their market relevance and topicality, into products and services on the market with the aim of generating income from their sale, licensing, or independent use (Bgantseva and Kovazhenkov, 2009). Herewith commercialization process implies search, assessment and selection of promising projects and developments as the results of intellectual activity for financing, fundraising, legal allocation of rights to IAR, its implementation into production, and further modification and maintenance of the manufactured product. In accordance with the current Russian legislation the commercialization of IAR in the University can be carried out through the execution of registered $R \& D$ with further patenting, by means of alienation of exclusive rights to the use of IAR by legal entities and individuals and through the creation of small innovation enterprises (SIE).

As far as the execution of registered R\&D is concerned, its main customer in Russian economy is the state. The analysis of the experience of federal and regional authorities shows that according to official and expert data only $5 \%$ of $R \& D$ results, conducted in Russia, are used in industrial production, whereas in the U.S.A. this number constitutes about $70 \%$. Russian companies are reluctant to invest their own money in research and elaborations. They are focused on the purchase of foreign technologies and equipment which are successfully tested and applied in the countries of their production.

It should be noted that in our country the procedure of granting rights to the use of RIA and alienation of exclusive rights is not sufficiently developed in comparison with other countries. More than that, in Russian practice there has appeared a negative trend to reduce the number of contracts of alienation of patents and licensed agreements. In 2014 their number decreased up to $5 \%$ if compare with 2013. One of the main causes of the low level of license market development is the lag (retardation) of Russia in the development of experimental-industrial production in comparison with the countries of the developed technological market. This lag is largely connected with the fact that as a result of recent structural changes in the economy of Russia in the following chain "fundamental science - applied science implementation of technologies" there appeared a discontinuity - In fact industry-specific research institutes ceased to exist. Thus, in particular, according to Rosstat, in 2013 the development and implementation of technological innovations carried out $8.9 \%$ of the total number of enterprises of domestic industry, which is significantly below the values typical of Germany (70\%) and even of Estonia (55\%) and the Czech Republic (36\%). Foreign experience indicates a relatively successful experience of the universities in the field of IAR commercialization through licensing. According to foreign studies, more than half of the patents of the universities possesses license agreements (Yonghong et al., 2014). And at first foreign companies bring their technologies to the level of a demanded competitive product for years, successfully introducing them to their market, and then, in accordance with their popularity patent them in other countries for the development of foreign markets. High indexes of IAR sales indicate the presence of a highly competitive market of intellectual property. In Russian economy the share of state-owned enterprises, science-research institutes and universities, which have signed the contract on alienation of exclusive rights to inventions, patents, industrial samples (models), within the period from 2009 to 2013 had a tendency to increase. In 2013 the given indicator increased by 8.2\% thus made $17.1 \%$. This is due to the growing need of university developers in IAR commercialization through the activities of small innovation enterprises established within the framework of the Federal Law №217, according to which a mandatory (obligatory) procedure is to transfer the right to the use of IAR by the University to the established business company by right of non-exclusive or exclusive license. However, according to Rospatent of the Russian Federation (The 
Russian Federal Service for Intellectual Property), in 2014 the share of universities and science-research institutes in the sphere of transfer of these contracts decreased up to $10.67 \%$. Compared with foreign universities, the index of transfer of the rights to the use of intellectual activity results remains quite low.

Presently the most widespread way of intellectual property commercialization has become creation of small innovation enterprises in the University. The aim of SIE creation is the adaptation of University research results and developments to the requirements of real sector of economy and their embodiment into new products or services with subsequent implementation on the market. Herewith the University can be its founder single-handedly, as well as to involve other persons as co-founders of this enterprise. Thus, the provisions of the Federal Law №217 dated from 02.08.2009, which allows the universities to create SIE, have opened opportunities for the development of effective mechanisms of interaction between science-educational and productive sectors of economy. The transformation of the regulatory-legal base governing the establishment of small enterprises at universities is conditioned by entry into force in 2013 the Federal Law №273-FL "On education in the Russian Federation" amendments and addenda to the Civil Code of the Russian Federation, etc. One of the most significant changes is the deregulation of the University share in the authorized capital of the established enterprise. However, despite the changes in legislation, aimed at improving investment attractiveness of small enterprises and flexibility of the processes of IAR commercialization in the universities, the activity of the universities in the creation of small enterprises has noticeably declined. In 2014 there were created small enterprises by 28\% less than in 2013 and by 56\% less than in 2010 .

Deterioration of the key indicators of IAR commercialization in universities is a reflection of the decline in their innovation potential due to the following reasons:

- scientific research and developments of the universities are often torn off from the needs of real sector;

- the activity of developers and agents of innovation university infrastructure is often only formally focused on the commercialization of innovations, but actually just on the writing of reports;

- the algorithm of the process of commercialization is nonexistent whereas the existing agents of innovation infrastructure are weakly interconnected;

- in universities there is no effective system of motivation and stimulation of researchers in IAR commercialization;

- entrepreneurial culture is not sufficiently developed in the universities.

The necessity of solution of these problems and tasks of transformation of the universities into a recognized source of technologies, human resources and knowledge forms the need to establish University innovation ecosystem for innovation commercialization. The notion of "ecosystem" was introduced into scientific circulation by English botanist A. Tansley; by this term he understood any set of jointly inhabiting organisms and their environment (Tansley, 1935). In other words, an ecosystem is a system of energy exchange, interrelations between its participants. The application of the concept of ecosystems to solve the problems of innovation process let identify their causes, as well as to model prospects. In this regard, it is expedient to study the mechanism of innovation commercialization from ecosystem approach standpoint. The focus of ecosystems study in relation to innovation process and community of its participants is conditioned by the development of the concept of open innovations (Chesbrough, 2003), in the basis of which lies massive outsourcing and formation of global value chains. The concept of innovation ecosystem was proposed by Charles W. Wessner (2007). It offers a tool to create conditions contributing to increase in competitiveness of organizations in national and regional economies. In the heart of the concept is the idea of innovation as a process of idea transformation into a commercial product or a service which demands much collective efforts of the participants: companies, universities, research companies, venture funds and others. Innovation ecosystem unites all these efforts, thus providing an opportunity to achieve a synergistic effect.

Ecosystem approach considers as well innovation systems of different levels (national, regional, clustered, etc.) as living social organisms (Owen, 1980) subjected to continuous changeability under the influence of new motivations of the participants and new circumstances. The transformation of the universities into a major factor of knowledge-based society carries in itself the idea of innovations' creation. A new mission of the universities is becoming a capitalization of knowledge (Etzkowitz, 2003); therefore, the main directions of their work should become transfer of the results of intellectual activity, technologies into the sector of production of goods and services as well as topical scientific and scientific-technical tasks into the sector of research and developments. To solve the assigned objectives higher educational institutions must possess the necessary components which, on the one hand, will form abilities, skills, experience, competencies for innovations implementation and enterprise management, and, on the other hand, contribute to resources formation for reproduction and constant development. Thus, ensuring of effectiveness of the innovation process in a higher educational institution can be achieved through the formation of an innovation ecosystem. An innovation ecosystem of a higher educational institution is a complex of interrelations of the agents of an innovation 
process with the aim of innovations commercialization. By analogy with a biological ecosystem, the activities of the agents of the innovation ecosystem can be characterized from the point of view of their communion to certain "ecological niches". To the main agents of the innovation ecosystem can be referred the following:

- $\quad$ the customers, who form demand for innovation products;

- the developers of innovation ideas;

- the institutions of innovation infrastructure of the University (business-incubators, centres for technology transfer, management of intellectual property protection, etc.).

At the same time the innovation ecosystem of the University, even possessing all the necessary infrastructure components, will not be effective if in the future the resources, invested in research, will not be embodied into innovations, which make a profit, what, in its turn, is reflected in the commercial format of the University. Thus, integrated approach to the analysis of University innovation ecosystems requires not only the study of their participants, but also peculiarities of their interaction and environment - culture, technology, resources, in particular.

\section{Discussion}

The relevance and necessity of innovation ecosystem development is confirmed by increasing interest of universities, business communities and public authorities towards participation and organization of diverse forums and programmes in this direction. Russian venture company and business incubator "Ingria" carried out a study of development of innovation ecosystems in Russian universities and research centers, in the process of which a methodology of innovation ecosystem measuring was proposed and barriers for technology transfer were identified (The development of innovation ecosystems of universities and research centers, 2015). In accordance with this methodology four basic parameters of innovation ecosystem measuring are distinguished: purposiveness, agents, relations between them and the environment which provides resources for the agents.

It is obvious that there is no universal model of University innovation ecosystem. Each University is unique in terms of its resources, exigencies, opportunities, motives and barriers in the field of innovations. However, regardless of these peculiarities, the purpose of functioning of innovation ecosystem of the University consists in implementation of the process of innovations commercialization which has a definite result in the form of introduction of products to the market. The functioning of the innovation ecosystem is aimed at providing consistent, continuous commercialization process converting the flow of ideas, developments and competencies of the teams into assets with their subsequent sale. At the same time the agents of the innovation infrastructure of the universities do not always possess stimuli to convert innovation ideas into commercial products. Less than $5 \%$ of University developments reach the stage of implementation into industry (Osipov et al., 2014). The reason for this is that the financing of the developments of Russian universities by more than $90 \%$ is carried out at the expense of the state and is connected with major state projects which are focused on the stage of "startup ideas". Thus, the developers are fully motivated to take part in early stages of project development with simultaneous absence of necessity to search for manufacturing company and implement their developments.

The innovation ecosystem will function successfully only in case of diversity assurance of its agents possessing the necessary resources, competencies and targets. In particular, a variety of customers in University innovation ecosystem is determined by the network of partnership relations with the enterprises of real sector of economy as well as technological platforms, cluster-based and other integrations in the field of innovation. The effectiveness of University innovation ecosystem is also achieved by way of involving the representatives of business communities as mentors and experts into the process of technology transfer.

One of the most effective mechanisms to involve developers into the process of creation and transfer of the results of intellectual activity is considered to be financial incentives (financial stimulation). Financial stimulation of the developers (the authors of IAR) in universities is carried out mainly through the disposal of the exclusive right to IAR. The developers get a reward (a bonus) paid from the payments under license agreements and contracts of alienation of rights to IAR or disposal of the right to IAR. The reward is also received by structural units in which IAR are created. Such form of material incentives is used in NRU The Higher School of Economics (NRU HSE), Ural Federal University, Don State Technical University, etc. Especially interesting is the NRU HSE experience in the field of material incentives for the creation of IAR. The developers receive a nonrecurrent incentive fee for IAR creation after receiving a security document in favour of NRU HSE (or in partnership with third persons) (Smirnova, 2015). This form of material stimulation significantly increases the quantitative indicators of inventive activity of the University and is especially topical at the initial stage of development of the innovation ecosystem.

Characterization of the agents of innovation ecosystem infrastructure can be considered from the point of view of a commercialization process: from developments to asset formation and from assets to market transaction. D. Jackson 
(2011) notes that the basis of any model of the innovation infrastructure should contain two interrelated components, one of which is aimed at providing scientific research and developments, and the other - at supporting and stimulation of the process of commercialization of intellectual activity results. The second component of the innovation infrastructure takes into account the dynamics of complicated relationships, which are formed between its participants, whose functional task is to ensure the promotion of innovations, the provision of access to business acceleration services, the organization of access to financing on the part of business-angels and funds of pre-seed and seed investments. The majority of Russian universities has a sufficient number of agents of the innovation infrastructure who provide scientific research and developments. However, the components aimed at supporting and encouraging innovations are often not suffice. So, among nearly 200 business-incubators functioning presently only $28 \%$ are created under the jurisdiction of the universities (Problems and solutions: business-incubators and technoparks in Russia, 2014). Besides, the existing agents of the innovation infrastructure function inefficiently and discretely, what is confirmed by the low level of commercialization of intellectual activity results in Russian universities.

As an example of a developed innovation infrastructure can be given the experience of Don State Technical University (DSTU). Currently, the innovation infrastructure is presented by the agents focused on provision of scientific research and developments as well as on maintenance and stimulation of commercialization of intellectual activity results. The first group of the agents of innovation infrastructure includes:

- Management of research, the objectives of which embrace assistance in filing of applications and contract arrangements, accounting of publication activity, consulting services in the field of preparation and implementation of potential scientific projects, provision of activity coordination and synergy of efforts of subdivisions and services of the University in the process of scientific research organization and usage of the results of these studies;

- Youth innovation centre, the purpose of which is the development of scientific and technical potential, as well as the involvement of the students, postgraduates and young scientists into scientific-research work of the chairs, scientific-research departments of the University;

- South centre of modernization of mechanic engineering, which organizes the necessary supplementary testing, test pattern (prototype model) creation, etc.;

- three common use centers, five science-research laboratories.

The second group of agents of infrastructure providing support and stimulation of commercialization of intellectual activity results includes:

- Department of intellectual property, which provides registration and protection of intellectual activity results and contributes to transfer of the developments into real sector of economy;

- Business-incubator, which provides placing and consulting support for University business-teams;

- regional business-catalyst created with the support of Moscow school of management "SKOLKOVO" and JSC "Russian venture company". At the basis of its functioning lies the principle of acceleration. Business-catalyst is a professional "accelerator" of team training, formed on the basis of high-tech solutions (projects), for the creation of business ready for investing (Makarov and Ugnich, 2015).

At the same time, for the agents of the innovation infrastructure in addition to their quantitative diversity is no less important their functional contents.

Typical problems of functioning of the innovation infrastructure of many Russian universities are the following:

- inefficiency or absence of marketing technologies and competencies, search of commercial customers;

- $\quad$ inactive search of commercializable solutions on the use of IAR;

- absence of active search of copyrightable IAR;

- weak interaction between the departments of science research and developments and the departments responsible for promotion and stimulation of the commercialization of intellectual activity results.

Relying on foreign experience, it can be noted that in the structure of agents providing commercialization of an innovation project may be present as well the agents of financial support (for example, the Applied Research Fund of Tel Aviv University). For Russian universities such structures are characteristic to a lesser degree. Although the attraction of investments through the development of endowment funds has a successful experience, rather conservative Russian legislation regulating market activity of budget recipients (spending units) and development of endowment, does not fully allow to implement various forms of public-private partnership with the participation of the University. In Russian practice the main problem of functioning of the innovation ecosystem of the universities is the absence of unified standards for the activity of all its agents and their weak interconnections. Barrier preventing the interaction of agents within the innovation ecosystem of the University is the discontinuity of communications between the community of developers and the industry itself, the discontinuity between core subdivisions as well as core subdivisions and development team. Applied 
research activities are torn off from the needs of potential customers of real economy sector as they are often initiated by the developers within the framework of implementation of thesis works or academic grants. Foreign experience shows that the most successful ways of overcoming discontinuity with industrial enterprises are considered to be the establishment of joint funds for financing developments of early stages (for example, the Fund created by Israeli Company of technology transfer of Weizmann Institute KTT Yeda with the companies Teva and J\&J) and work in syndicates (consortia) (The development of innovation ecosystems of universities and research centers, 2015).

As far as the development of innovation ecosystem environment is concerned, many Russian universities face serious challenges of both subjective and objective character. In particular, a serious objective problem of development of the interaction between universities and industrial and business community is the absence of clearly defined requirement of Russian economy in the sphere of technology transfer and IAR commercialization created by the universities. At the same time, the mechanisms of functioning of Russian universities in general are not tuned to either industrial priorities or the priorities of local community, what is manifested at all levels of governance and in all spheres of Universities' activities, although due to intensive reforms of higher educational system, through the programs of development, a gradual forming of innovation ecosystems in leading Russian universities is taking place. Here as an example can be given innovation ecosystems of Lomonosov Moscow State University, ITMO University, Bauman Moscow State Technical University, NRU The Higher School of Economics, Tomsk State University of Control Systems and Radioelectronics and others. The success of innovation ecosystems of these universities is confirmed by a high relative share of income from R\&D in total income of the universities (over 20\%).

It should be noted that a successful innovation ecosystem of the University forms a suitable environment for commercialization itself; in particular, it can develop the necessary informal institutions such as partnership organizational culture. Partnership organizational culture corresponds to the greatest degree to a successful development of the innovation ecosystem. It contains at its core a dynamic entrepreneurial and creative origin, emphasizing development and acquisition of new opportunities, encouragement of innovation, improvisations, individual initiative and freedom. What is associated with success is the constant development of science research and entrepreneurial initiatives with the aim of providing unique and new products or services. For partnership organizational culture it is characteristic a flexible projectmatrix structure. At the heart of the values lies individual, social, cultural and moral creativity. It is partnership organizational culture what will allow the ecosystem of the University to implement the task connected with the formation of the competences of entrepreneurs-universalists who generate ideas, set tasks and resolve technological and organizational discrepancies in the modern world.

In our opinion, in the innovation infrastructure of the University along with the components for the provision of scientific research and their commercialization, must be a third functional constituent, aimed at the formation of partnership organizational culture and the necessary competences in the field of innovation entrepreneurship, marketing of the technologies, protection of intellectual property. The formation of these competences must be secured as a compulsory component in the educational programme of higher professional education for engineering specialties as well as through regular advanced professional training of employees and administrators of the elements of the innovation infrastructure of the University. The interaction of the three functional constituents of the infrastructure of University innovation ecosystem should contribute to the reduction of barriers on the way of commercialization of innovations connected with discontinuity of communications between agents, lack of marketing research, ill-developed partnership organizational culture.

Thus, the prospects of development of innovation ecosystems of the universities, contributing to successful IAR commercialization, are seen in realization of the following directions:

- $\quad$ the formation of precise priorities of scientific and innovation activity;

- $\quad$ the interaction consolidation between different elements of the University ecosystem;

- $\quad$ the development of relationships with venture capital funds and investors;

- $\quad$ the development of cooperation with enterprises of real sector of economy, including through active marketing resources of the University;

- the active search of projects, teams, and competences;

- $\quad$ the development of partnership organizational culture and competences of innovation entrepreneurship.

\section{References}

Bgantseva, Y.V. and Kovazhenkov M. A. (2009) Innovation management strategy of commercialization of intellectual property of the University Economic science, 9 (58) (in Russian)

Chesbrough, H. (2003). The era of Open innovation. Sloan Management Review, 3, 35-44. 
Etzkowitz, H. (2003). Innovation in Innovation: The Triple Helix of University-Industry- Government Relations. Social Science Information 42(3), 293-338 http://dx.doi.org/10.1177/05390184030423002.

Freeman, C. (1987) Technology Policy and Economic Performance: Lesson from Japan. Pinter Publisher.

Fukuda, K. \& Watanabe, C. (2008) Japanese and US perspectives on the National Innovation Ecosystem. Technology in society. Vol. 30, iss. $1 \mathrm{http}: / / \mathrm{dx}$.doi.org/10.1016/j.techsoc.2007.10.008.

Jackson, D.J. (2011) What is an Innovation Ecosystem? National Science Foundation, Arlington, VA, Retrieved from http://urenio.org/ wp-content/uploads/2011/05/What-is-an-Innovation-Ecosystem.pdf.

Lundvall, B.-A. (1992) National Systems of Innovation. Towards a Theory of Innovation and Interactive Learning. Pinter Publisher.

Makarov, S. \& Ugnich E. (2015) Business-catalysts as Drivers of Regional Innovation Systems. Foresight-Russia, vol. 9, 1, 56-67. http://dx.doi.org/10.17323/1995-459x.2015.1.56.67.

Mercan, B. \& Goktas D. (2011) Components of Innovation Ecosystems: A Cross-Country Study. International Research Journal of Finance and Economics. 76.

Nelson, R. R. \& Winter S.G. (1982) An Evolutionary Theory of Economic Change. Boston: Harvard University Press.

Osipov, G.V., Strikhanov M.N. \& Sheregi F.E. (2014) The interaction of science and industry: sociological analysis. Moscow: SFMC (in Russian).

Owen, D.F. (1980) What is ecology? Oxford: Oxford University Press.

Problems and solutions: business-incubators and technoparks in Russia (2014). Moscow: RVC, 3-5. (in Russian).

Smorodinskaya, N.V. (2014) Network innovation ecosystems and their role in the dynamization of economic growth. Innovations, 7 (189), 27-33 (in Russian).

Tansley, A.G. (1935) The use and abuse of vegetational terms and concept. Ecology, 16 (3), 284-307.

Smirnova, V.R. (2015) Topical issues of Economics and management of intellectual property. Monograph. Moscow: FSBEI HPE "RSAIP". (in Russian).

The development of innovation ecosystems of universities and research centers (2015). Sankt Petersburg: Ingria, RVC (in Russian).

Wessner, C.W. (2007). Innovation policies for the 21th century. (Report of a symposium. ed.). Washington, D.C.: The National Academies Press.

Yonghongm, Wu, Eric W. Welch \& Wan-Ling Huang (2014) Commercialization of university inventions: Individual and institutional factors affecting licensing of university patents. Technovation, 36-37, 12-25 http://dx.doi.org/10.1016/j.technovation.2014.09.004. 